\title{
Effects of shade stress on morphophysiology and rhizosphere soil bacterial communities of two contrasting shade-tolerant turfgrasses
}

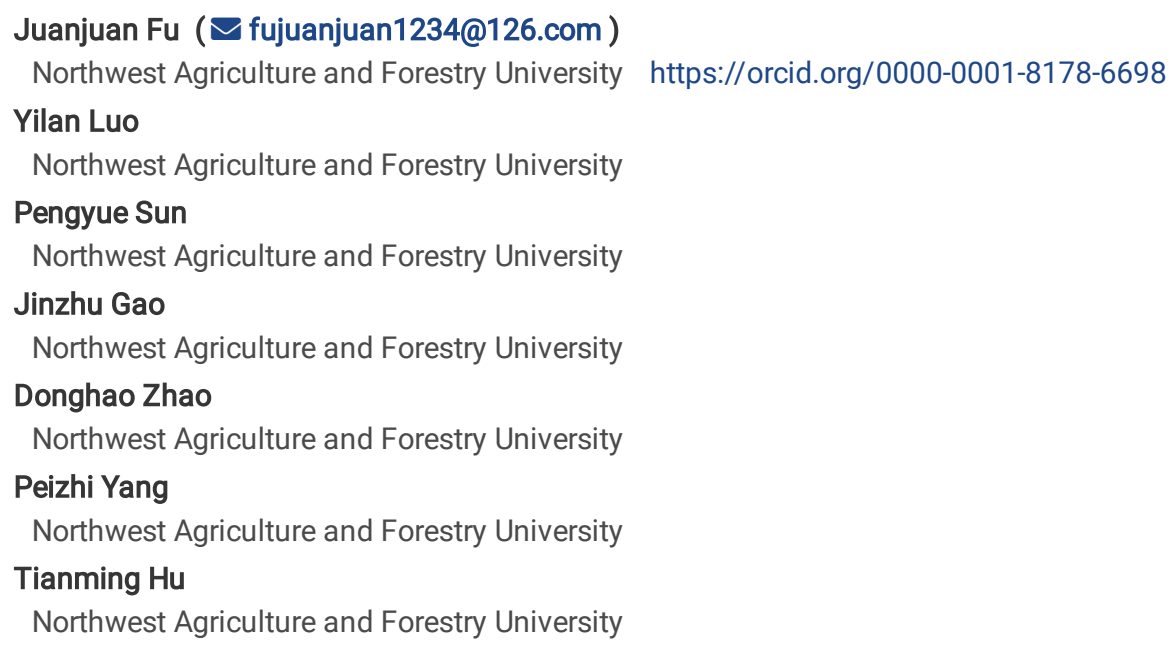

Keywords: Community structure and diversity, Plant-soil feedback, Rhizosphere bacteria, Shade stress, Shade tolerance, 16S rRNA gene sequencing Posted Date: October 14th, 2019

DOI: https://doi.org/10.21203/rs.2.16025/v1

License: (c) (1) This work is licensed under a Creative Commons Attribution 4.0 International License. Read Full License

Version of Record: A version of this preprint was published on March 2nd, 2020. See the published version at https://doi.org/10.1186/s12870-0202300-2. 


\section{Abstract}

Background: Shade presents one of the major abiotic limitations for turfgrass growth. Shade influences plant growth and alters plant metabolism, yet little is known about how shade affects the structure of rhizosphere soil microbial communities and the role of soil microorganisms in plant shade responses. In this study, a glasshouse experiment was conducted to examine the impact of shade stress on the growth and photosynthetic capacity of two contrasting shade-tolerant turfgrasses, shade-tolerant dwarf lilyturf (Ophiopogon japonicus, OJ) and shade-intolerant perennial turf-type ryegrass (Lolium perenne, LP). We also examined soil-plant feedback effects on shade tolerance in the two turfgrass genotypes. Bacterial community composition was assayed using high-throughput sequencing.

Results: Our physiochemical data showed that under shade stress, OJ maintained higher photosynthetic capacity and root growth, thus OJ was found to be more shade-tolerant than LP. Shade-intolerant LP responded better to both shade and soil microbes than shade-tolerant OJ. Shade and live soil decreased LP growth but increased biomass allocation to shoots in the live soil. The plant shade response index of LP is higher in the live soil than sterile soil, driven by weakened soil-plant feedback under shade stress. In contrast, there was no difference in these values for OJ under similar shade and soil treatments. Illumina sequencing data revealed that shade stress had little impact on the diversity of the OJ and LP's bacterial communities, but instead impacted the composition of bacterial communities. The bacterial communities were mostly composed of Proteobacteria and Acidobacteria in OJ soil. Further pairwise fitting analysis showed that a positive correlation of shade-tolerance in two turfgrasses and their bacterial community compositions. Several soil properties (NO3-N, NH4+-N, AK) showed a tight coupling with several major bacterial communities under shade stress, indicating that they are important drivers determining bacterial community structures. Moreover, OJ shared core bacterial taxa known to promote plant growth and confer tolerance to shade stress, which suggests common principles underpinning OJ-microbe interactions.

Conclusion: Plant shade tolerance is mediated by soil-plant feedback and shade-induced changes in rhizosphere soil bacterial community structure in OJ and LP plants.

\section{Background}

Urban greening currently employs a combination of trees, shrubs and grass, but beneath the trees and shrubs is the inevitable shady lawn. As a result, shade stress presents a major challenge to turf grass growth. It has been estimated that approximately $20-25 \%$ of all grassed areas in the USA [1], and $50 \%$ of turf grass in China, is subjected to varying degrees of shade [2]. The negative effects of shade on plant morphology and physiology have long been established $[3,4]$. Shade reduces the ratio of red (R) to far-red (FR) light causing elongation growth $[5,6]$, an increase in specific leaf area, a decrease in thickness [7, 8], and decrease in biomass [9]. Particularly, shade stress adversely impacts chlorophyll content, chloroplast ultrastructure, as well as photosynthetic physiological processes [10,11].

Shade stress also leads to lower air flow and directly alters soil humidity and temperature in a shaded environment. The changed soil humidity and temperature change the physicochemical properties of soil. The changed microclimates caused by shade stress influence soil microbial structure and diversity [12]. Numerous studies suggest that plants' responses to abiotic stresses may be mediated by soil microorganisms [13,14]. Dahl et al. [15] pointed out that warming and shading changed fungal community composition in Arctic soils. A recent study further demonstrates that soil microbial communities could influence plant responses in shade stress [16]. However, there is little understanding of how shade influences the soil bacterial communities of turf grasses and the relationship between shade tolerance and those communities.

Dwarf lilyturf (Ophiopogon japonicus (Linn. f.) Ker-Gawl, OJ) is an important green plant in the Liliaceae family with strong inherited shade tolerance. Lolium perenne (LP), is one of the most important shade-intolerant cool-season perennial turf-type ryegrasses in temperate climates. In the current study, we investigated the effects of shade on the plant photosynthetic capability and the rhizosphere soil bacterial communities of $0 \mathrm{~J}$ and LP grown in the same lawn under different light conditions. We also analyzed soil-plant feedback effects in both plant species. The following hypotheses were tested: i) shade tolerance is modified by soil microorganism due to soil feedback effects; ii) the different shade-tolerances in the two plants correlate with an altered soil bacterial community composition; iii) the altered rhizosphere bacterial community structure is due to shadeinduced changes in soil chemistry and differing photosynthetic capabilities.

\section{Results}

\section{$O J$ and $L P$ seedling growth and plant traits}

OJ and LP seedlings were exposed to shade stress and examined to determine their growth response to this stress (Fig. 1, Additional file 1: Table S1). Shade treatment resulted in different growth suppression in the two plants. Shade did not significantly influence leaf area in OJ but resulted in a $14.9 \%$ decrease $(P<0.05)$ in LP leaf area when leaves were exposed to $14 \mathrm{~d}$ of shade stress compared to non-shade (Fig. 1A). Shade treatment significantly decreased $(P<0.01)$ total root length, root surface area, and root volume in LP, while OJ exhibited superior acclimation to shade stress (Fig. 1B-D). In addition, OJ and LP had different changes in chlorophyll content in response to shade stress. Shade stress increased chlorophyll content in OJ, while shade stress reduced chlorophyll content in LP (Fig. 1E). Fluorescence parameters $\left(F_{v} / F_{m}\right)$ for chlorophyll a were reduced 
significantly in LP compared with OJ, indicating that OJ maintained higher photosynthetic capacity under shade stress (Fig. 1F). These results demonstrate that $\mathrm{OJ}$ is more shade-tolerant than LP.

Shade-intolerant LP was more responsive than shade-tolerant OJ to shade and soil microbes (Fig. 2; Additional file 2: Table S2). Shade stress negatively affected total LP plant biomass during the experimental period, but no significant change was observed in OJ (Fig. 2A, B). The total dry biomass and shoot biomass in LP were lower in live soil compared to those in sterile soil. This occurred both under non-shade and shade stress. In contrast, no significant difference was observed in OJ under the same conditions.

For LP, root: shoot ratios were higher in the shade compared to non-shade conditions. LP also exhibited higher ratios in sterile compared to live soil under shade stress, however there was no significant difference in light response between live and sterile soil (Fig. 2C). Shade significantly increased $(P<0.05)$ LP specific root length, but we observed no significant change between sterile and live soil. We did observe a slight difference of specific root length in OJ under light and soil treatments (Fig. 2D).

As observed with LP specific root length, LP specific leaf area only responded to shade treatment, with higher values $(P<0.05)$ in shade compared to non-shade (Fig. 2E). Plant leaf and root $N$ content showed significant responses $(P<0.05)$ to shade treatment. The synergistic effect of shade treatment and the presence of soil microbes on root and leaf $\mathrm{N}$ was not significant (Fig. 2F, G; Additional file 2: Table S2). Compared to non-shade treatment, shaded plants in sterile soil had a $17.18 \%$ decrease in leaf $\mathrm{N}$ content and shaded plants in live soil displayed a $36.52 \%$ decrease in leaf $\mathrm{N}$ content. LP root $\mathrm{N}$ content decreased $18.73 \%$ and $24.57 \%$ in shaded versus non-shaded plants under sterile and live soil treatments, respectively. For OJ, shade increased the $\mathrm{N}$ content in live soil: $30.61 \%$ in leaves and $33.01 \%$ in roots. The corresponding values for shaded sterile soil were $26.58 \%$ and $28.45 \%$ for leaves and roots, respectively (Fig. $2 F, G$ ).

Soil treatment and species interaction significantly affected plant shade response index (Fig. 3A; Additional file 3: Table S3). In LP, the plant shade response index responded to soil treatments with significantly higher values $(P<0.05)$ in live soil versus sterile soil, while there was no difference in OJ (Fig. 3A). Also, shade and species interaction had a significant effect on soil-plant feedback index (Fig. 3B; Additional file 3: Table S3). Soil-plant feedback index in LP was consistently lower $(P<0.05)$ in shade compared to non-shade treatments, but there was no difference in the value of $0 \mathrm{~J}$ between highlight and shade treatments (Fig. 3B).

\section{Soil chemical characteristics}

Shade stress significantly influenced most of the physicochemical properties analyzed (Table 1). Both OJ and LP soil showed significant increases in the $\mathrm{NO}_{3}{ }^{-}-\mathrm{N}$ content with shade treatment $(P<0.001)$. Conversely, shade treatment decreased TP, TK and AK in both soil types compared to nonshade treatment, with a greater effect with LP soil. Shade treatment of OJ resulted in a significant decrease in rhizosphere $\mathrm{NH}_{4}{ }^{+}-\mathrm{N}_{\text {and }}$ a significant increase in the rhizosphere AP content. The opposite trend was observed with LP. Shade treatment had a small effect on the soil TN, SOC, C:N ratio, and rhizosphere $\mathrm{pH}$ level.

\section{Bacterial diversity and community composition response to shade stress}

Amplicon products of the V4 region of the 16S rRNA gene were obtained from each of the 60 samples and sequenced using the Illumina HiSeq 2500 platform. A total of 5,371,314 bacterial clean reads were obtained. These sequences were grouped into 11,485 OTUs according to a $97 \%$ similarity threshold. According to the rarefaction curves (Additional file 4: Figure S1), the sequencing depth in these samples was sufficient to cover the full diversity.

The OJ and LP rhizosphere soil bacterial communities did not have similar alpha diversity features, as measured by the OTU richness, Shannon's diversity index $(\mathrm{H})$ and Simpson's Evenness (E) (Fig. 4). The OTU richness and diversity did not show significant differences between the two rhizosphere soils. However, the evenness increased $(P<0.05)$ in OJ soil under shade stress but decreased in LP soil. This suggests that a few numerically dominant OTUs inhabit the LP rhizosphere.

The patterns of bacterial community composition between treatments in OJ and LP soils were analyzed using PCoA based on Bray-Curtis dissimilarity. The PCoA analysis explained $64.06 \%$ of variation (two axes) in bacterial community composition. Shade treatments led to a distinct bacterial community structure (PERMANOVA, $P<0.05$ ), and the bacterial community structures between the OJ and LP rhizosphere soils were also obviously different (Fig. 5). Further evidence showed that the bacterial communities collected within the OJ rhizosphere on the one hand, and JP rhizosphere on the other, overlapped partially in the PCA plot (Additional file 5: Figure S2), indicating that OJ and LP soils had different bacterial community structures.

In both OJ and LP rhizospheric soil, the edaphic bacterial communities harbored 11 different phyla (accounting for more than $93 \%$ in each sample). The most numerically dominant phyla were Proteobacteria followed by Acidobacteria and Thaumarchaeota (Fig. 6A). Proteobacteria, Actinobacteria, and Chloroflexi decreased in LP soil in response to shade stress, but an increase or a lower degree of change was observed in OJ soil. In contrast, shade led to higher abundances of Verrucomicrobia and Acidobacteria in LP soil, compared to OJ soil (Kruskal-Wallis, $P<0.01$ ). 
There were 12 genera (>0.5\%) within the classes Alpha and Gamma Proteobacteria, Flavobacteria, Planctomycetia, Spartobacteria, Nitrospira, and Thaumarchaeota. The genus Candidatus Nitrososphaera was clearly dominant within the taxonomic structure of the bacterial community (Fig. 6B). The most evident differences between $\mathrm{OJ}$ and LP rhizosphere soil bacterial communities were the opposing trends in the abundance of Nitrospira, Steroidobacter, Kaistobacter and Pirellula. These genera were unchanged or increased with increasing shade treatment in OJ soil, but they tended to decrease in LP soil. In contrast, the relative abundance of Rhodoplanes, Planctomyces, and Pseudomonas was larger (Kruskal-Wallis, $P<0.01$ or $P<$ 0.001 ) in OJ soil under shade treatment, compared to LP soil. In LP soil Gemmata was more abundant than in OJ soil (Kruskal-Wallis, $P<0.001$ ), although shade stress decreased the relative abundance of this genus in both soils.

\section{Core microbial players associated with rhizosphere soil in OJ and LP}

The core bacteriome of $\mathrm{OJ}$ and LP rhizosphere soils was determined to examine shifts in the bacterial communities observed with the different host types. This analysis suggested that a specific taxonomy may exist which is particularly well adapted and prominent under different growth conditions. We found that OJ rhizosphere soil was dominated by OTUs identified as: Nitrosovibrio (19.1\% of total core bacterial OTU), Aquicella (12.5\%), Planctomyces (11.8\%), Pseudomonas (11.2\%), Nitrospira (10.3\%), Steroidobacter (10.3\%), Flavobacterium (8.8\%), Kaistobacter (5.2\%), Bacillus (6.8\%), and Rhodoplanes (5.1\%), which mostly belongs to Proteobacteria. In contrast, the LP rhizosphere soil was dominated by Acinetobacter (21.0\%), Flavisolibacte (19.3\%), and Skermanella (17.1\%) (belonging to Proteobacteria and Bacteroidetes, respectively). Nitroso vibrio tenuis and Candidates Nitrososphaera_SCA1145 (both 5.9\%) were identified in theOJ rhizosphere soil core (Additional file 6: Table S4).

\section{Relationships between shade-tolerant parameters and bacterial communities}

There was a significant positive relationship between plant shade tolerance and soil bacterial community composition (Fig. 7). Among all the shade-tolerant indicators measured, leaf area, $F_{v} / F_{m}$, chlorophyll content, and root morphology were correlated with soil bacterial community composition $(P<0.001$ for all).

\section{Relationships between bacterial community and environmental variables}

The OJ and LP soil bacterial community structures displayed clear, individual correlations $(P<0.001$ or $P<0.05)$ to soil physicochemical variables including $\mathrm{NH}_{4}{ }^{+}-\mathrm{N}, \mathrm{NO}_{3}{ }^{-}-\mathrm{N}$, and TK as shown by the Mantel test (Additional file 7: Table S5). CCA analysis revealed that the OJ and LP rhizosphere soil bacterial communities were affected differently by edaphic chemical parameters under the shade treatments examined. The proportion of total variability of OJ and LP soil bacterial communities attributed to the explanatory variables was $73.21 \%$ and $82.57 \%$, respectively. This partition of variability was significant (general permutation test, $P<0.01$ or 0.05 ; 999 replicates; Fig. 8; Additional file 8: Table S6). AK and total N were the major factors affecting the bacterial assemblages in OJ soil as judged by the length of the vectors shown in our CCA plots. In OJ soil, AK and total $\mathrm{N}$ were positively correlated $(P<0.05)$ with Gemmatimonadetes, Chloroflexi, Acidobacteria, Nitrospirae, and WS3. For OJ soils, CCA was consistent with the trends revealed by PCA showing a clear separation between control and shade treatment (Additional file 5: Figure $\mathrm{S} 2$ ). The TN, $\mathrm{NO}_{3}{ }^{-}-\mathrm{N}$, and $\mathrm{NH}_{4}{ }^{+}-\mathrm{N}$ concentrations, three directly interlinked parameters, had a strong effect on bacterial assemblages in the LP soil. TN and NH${ }_{4}^{+}-\mathrm{N}$ were positively correlated $(P<0.05)$ with Actinobacteria, Bacteroidetes, and Thaumarchaeota. Taxa, such as Verrucomicrobia, Chloroflexi, Acidobacteria, Planctomycetes, Gemmatimonadetes, and WS3 were positively correlated $(P<0.01)$ with $\mathrm{NO}_{3}{ }^{-}{ }^{-} \mathrm{N}$. Additionally, shade treatments of different durations separately clustered in LP soil.

\section{Discussion}

The current knowledge of the plant shade stress response has arisen from studies of physiology and morphology and has neglected the contribution of soil-plant interactions to shade tolerance. This work used two turfgrass genotypes with contrasting shade tolerance to investigate the plant growth response induced by shade and the role of soil microbial communities in this response.

Physiological responses of OJ and LP plant to shade stress

We uncovered several differences between OJ and LP through analysis of the photosynthetic response and growth suppression that accompanied shade stress. Our physiochemical data demonstrated that shade stress resulted in more severe growth suppression in LP than in OJ, as compared to their respective sunlight treatments. This was indicated by a larger decline in leaf area, total root length, root volume, and surface area in LP versus OJ under shade stress. Similar results have been observed in several tree species, showing that shade-tolerant red oak had greater leaf area and dry mass than shade-intolerant species [4]. Plant photosystem II is sensitive to various environmental stresses, including shade stresses [17]. Chlorophyll a fluorescence $\left(F_{v /} F_{m}\right)$ is a valuable indicator of stress tolerance $[10,18]$. Our results show that under shade stress $0 \mathrm{~J}$ maintained higher $F_{v /} F_{m}$ and chlorophyll $(a+b)$ content, but no significant difference was observed in sunlight, suggesting OJ has a better photosynthetic capacity under shade stress. These findings suggest that $\mathrm{OJ}$ is more shade-tolerant than LP.

Plant shade tolerance is mediated by soil-plant feedback

Page $4 / 18$ 
Given that soil microorganism could directly and indirectly affect most plant functional traits[14]. We analyzed the role of soil-plant feedback to plant shade tolerance to further clarify the different shade tolerance mechanisms of OJ and LP. We found that shade stress reduced whole-plant biomass, and affected shoots and roots in LP, with no change observed in OJ. However, shade induced dry biomass reductions in LP were significantly lower in live soil treatments compared to sterile soil. This resulted in a less negative plant shade response index in live soil treatments, consistent with the recent study in two Bauhinia tree species with contrasting shade tolerance [16].

The present data agrees with our first hypothesis that plant shade tolerance would be modified by soil microorganisms. Plant biomass in LP was lower in live soil treatments. This agreed with previous studies showing that soil microorganisms have negative feedback effects on plant growth $[19,20]$. Soil microorganism-induced declines in LP biomass were accompanied by reductions in plant $\mathrm{N}$ content, indicating that soil microbes may compete with plants for nitrogen [21].

As with the interactions observed between soil microbes and shade on plant biomass, the interactive effects on soil-plant feedback was greater for LP compared to OJ. Shade-tolerant OJ plants are less sensitive to soil microbe-mediated soil-plant feedback due to a higher defense against soil pathogens and lower dependence on symbionts [22]. Also, both OJ and LP allocated more biomass to shoots in live soil compared to sterilized soil as shown by lower root: shoot ratios in live soil. This effect is an adaptive response to a limited light resource. Plants have ability to adjust their traits and patterns of biomass allocation to capture limited resources and maintain carbon gain[23].

\section{Plant shade tolerance is related to bacterial community composition}

Observed shade-induced changes in soil feedback were accompanied by a shift of soil bacterial community structure. In both OJ and LP, we found that shade stress had little impact on bacterial richness and soil community diversity. This is consistent with other studies showing that community diversity is not significantly impacted by drought $[24,25]$. Similar results have been reported in salt stress demonstrating that increasing salinity has no effect on total bacterial community richness [26]. The observed shifts in the soil microbiome when OJ and LP were shade stressed involved changes in relative bacterial abundance, rather than outright abolition of shade susceptible taxa and concomitant appearance of tolerant ones. This helps explain the lack of change in alpha-diversity.

$\mathrm{OJ}$ and LP rhizosphere soils with various shade treatments had significantly different bacterial community compositions. Proteobacteria and Actinobacteria have been shown to accumulate in OJ soil in response to shade stress, while they have been shown to decrease in LP soil. Prior studies have shown that Proteobacteria and Actinobacteria response to various environmental stresses, such as drought, salt and heavy metal stresses [27-30]. Actinobacteria are implicated in promoting plant growth under stress [31]. Many of them are known to form spores, which are resistant to adversity and can survive under stress conditions [32, 33].

Alpha and gamma Proteobacteria play a vital role in OJ soil in response to shade stress, as indicated by greater increase in genera of Kaistobacter, Steroidobacter, Pseudomonas observed in OJ soil. Inoculants of plant growth-promoting rhizobacteria (PGPRs) genera such as Pseudomonas, Flavobacterium, and Arthrobacter have been shown to ameliorate stress in plants by mediating a variety of physiological and biochemical changes [34-37]. Our study shows that species such as Nitrosovibrio_tenuis, Reyranella_massiliensis, Arthrobacter_psychrolactophilus, and Flavobacterium_succinicans, which belong to phyla of Proteobacteria, Actinobacteria and Bacteroodetes,are more abundant in OJ soil. This suggests that $\mathrm{OJ}$ prefer these genera and they may be markers of better shade-tolerance in OJ.

To further clarify this assumption and study the correlation of shade-tolerance parameters and bacterial community composition, pairwise fitting analyses were performed to compare above and below-ground morphology, photosynthetic capacity and bacterial community composition. We found that the leaf area, root volume, surface area, $F_{v} / F_{m}$, and chlorophyll $(a+b)$ content were positively and significantly related to soil bacterial community composition. This observation is in line with our second hypothesis, and with the last part of our third hypothesis. Similar observations have been shown in maize with differing aluminum tolerances, where it was observed that maize cultivars that depended on Al tolerance altered their root morphology and rhizosphere diazotrophic community composition [38].

\section{Changes in soil physicochemical properties play an essential role in shaping bacterial communities under shade stress}

Soil acts as a strong ecological filter affecting the bacterial community structure and diversity. Numerous studies of microbial communities under abiotic stress have shown that soil factors govern microbial community structure [39-41]. Bottomley et al. [42] observed that soil $\mathrm{NH}_{4}{ }^{+}-\mathrm{N}$ was a dominant environmental factor that influenced bacterial community structures. This is due to the fact that soil $\mathrm{NH}_{4}{ }^{+}-\mathrm{N}$ is the main nitrogen source for bacteria as seen by ${ }^{15} \mathrm{~N}$ isotope tracing [43]. Similarly, Nguyen et al. [44] also reported that cotton field soil bacterial diversity and composition were related to soil $\mathrm{NH}_{4}{ }^{+} \mathrm{N}$ and total $\mathrm{N}$ content exposed to post-waterlogging or post-prolonged drought. Consistent with our third hypothesis, AK and total $\mathrm{N}$ were the major drivers in $\mathrm{OJ}$ rhizosphere soil and they were positively associated with Gemmatimonadetes, Chloroflexi, Acidobacteria,

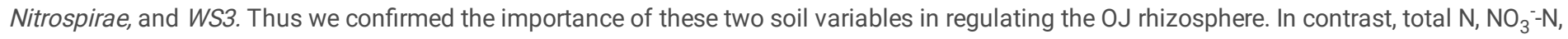
and $\mathrm{NH}_{4}{ }^{+}-\mathrm{N}$ concentration affect bacterial assemblages in LP soil. A strong relationship between soil physicochemical properties and bacterial

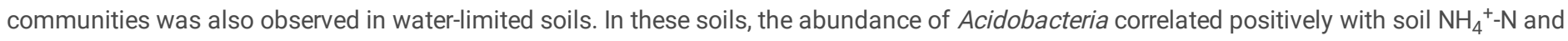
total P and negatively with total $\mathrm{N}$ and $\mathrm{Mg}^{2+}$, whereas Chloroflexi displayed the opposite trend [45]. 
In both control and stressed soil, host species were confirmed to influence bacterial community structures [46]. Our PCoA data shows that bacterial communities separated between OJ and LP soil. Al-tolerant maize cultivation significantly influenced the diazotroph populations [38], a result that aligns with our results with turfgrass. This may be mainly attributed to plant root exudates, which are key determinants of microbial community composition in plant-microorganism interactions [47].

\section{Conclusion}

This study describes the plant growth and photosynthetic response to shade stress as well as soil-plant feedback effects of shade tolerance in the two turfgrass genotypes. Maintenance of higher photosynthetic capacity and root growth during shade stress in OJ could make this a more shadetolerant species than LP. Shade-intolerant LP was more responsive to both light and soil microbes compared to shade-tolerant OJ. Moreover, plant shade tolerance is mediated by soil-plant feedback and shade-induced changes in rhizosphere soil bacterial community structure in OJ and LP plants. This study also showed that under shade stress, some soil properties showed a tight coupling with several major bacterial communities, indicating that they are important drivers determining bacterial community structures. This work assist the development of strategies to combat shade in turf grasses management and future studies of plant-microbe interaction under shade stress in turf grasses.

\section{Methods}

\section{Glasshouse experimental setup and soil sampling}

A glasshouse experiment was conducted at Northwest Agriculture \& Forestry University, China, using soils collected from two different turfgrasses: dwarf lilyturf (O. japonicus) and perennial ryegrass (L. perennecvs.ph.D.). The seeds were obtained in June 2017, from Bcyseed Co., Ltd., located in Liwan District (23.072127N, 113.207089E), Guangzhou, China. The specimen was purchased by Bcyseed Co., Ltd., a professional seed production and sales company, who undertook the formal identification of the seeds used in this study. Based on the unlikeliness of an erroneous identification, we have not deposited a voucher specimen. In this study, dwarf lilyturf (OJ) and perennial ryegrass (LP) were planted around the university campus on the same lawn: OJ (shade-tolerant) was grown around buildings and trees and LP (shade-intolerant) was planted in the center of the lawn that served as a greening square with good light conditions. The site has a warm temperate continental monsoon climate, with a mean annual air temperature of $12^{\circ} \mathrm{C}$ and $500 \mathrm{~mm}$ of mean annual precipitation. Before the experiment, the sites were managed as turfgrass for over 10 years.

To understand the physiological mechanism of contrast shade tolerance between OJ and LP, we investigated the responses of plant root growth and photosynthetic capacity to shade stress. The twoplants were cultured in a plastic pot $(13.5 \times 17.5 \times 11.0 \mathrm{~cm})$ filled with soil collected from their respective areas of growth, as described above. Seeds were superficially disinfected with $0.1 \%$ sodium hypochlorite and washed three times with purified water. Three seeds were sown per pot directly into the soil. The plants were maintained in a greenhouse with an average temperature of $23 / 18{ }^{\circ} \mathrm{C}$ (day/night), $700 \mu \mathrm{mol} \mathrm{m} \mathrm{m}^{-2} \mathrm{~s}^{-1}$ photosynthetic active radiation from natural sunlight, and $65 \%$ relative humidity until the plants grew above $15 \mathrm{~cm}$. Shade treatments were performed under the canopy using two layers of black nylon net using the same conditions described above. Pot treatments were randomized within a glasshouse compartment. We carried out five treatments including: (1) Control (0 d); (2) shade for $7 \mathrm{~d}$; (3) shade for $14 \mathrm{~d}$; (4) light (sunny) for $7 \mathrm{~d}$; (5) light (sunny) for $14 \mathrm{~d}$. There were six replicates per treatment, giving a total of 60 pots. After shade treatment, total leaf area, root morphology, chlorophyll content and the maximum quantum yield of PSII $\left(F_{v} / F_{m)}\right.$ were measured.

To further clarify whether soil bacterial communities directly or indirectly influenced the shade tolerance, we carried out a soil-plant feedback experiment. Soil in the $0-15 \mathrm{~cm}$ soil layer was collected beneath $\mathrm{OJ}$ and LP turfgrasses grown the same lawn as the first experiment. After the soil from under each plant type was pooled and homogenized, half of the soil was kept at $4{ }^{\circ} \mathrm{C}$ whereas the remainder was steam-sterilized for $3 \mathrm{~h}$ at $121^{\circ} \mathrm{C}$ and then kept at $4{ }^{\circ} \mathrm{C}$ until the start of the experiment [20].

A split-plot design with 12 blocks was applied in the soil-plant feedback experiment [48]. Light treatments (sunlight, shade) were established on whole blocks. Treatments of soil biota (live, sterile) and species (OJ and LP) were set up within blocks. Each treatment combination was replicated six times, resulting in a total of 48 pots. Seeds were surface-sterilized and germinated in plug trays filled with sterilized sands until the plants grew above $3 \mathrm{~cm}$. The seedlings were transplanted in pots filled with a mix of sterilized sand and either sterilized or live soil collected from beneath $0 \mathrm{~J}$ and LP turfgrasses (sand: soil volume ratio of 9: 1).

The seedlings were placed in the greenhouse for eight weeks, during which time they were irrigated twice weekly and monitored for various parameters. Two weeks after transplanting, Hoagland solution the was supplied to each pot. Pots were randomly located in the greenhouse and rearranged weekly to avoid possible positioning effects. Shade treatment was performed on eight-week old seedlings using two layers of black nylon net in the same greenhouse conditions as the first experiment. After four weeks of shade treatment, the seedlings' dry biomass was analyzed.

To further investigate soil bacterial communities and the difference between OJ and LP plants, we further analyzed the effects of shade stress on their rhizospheric soil bacterial communities. The rhizosphere soil collected from beneath OJ and LP turf grasses as above-mentioned in the plant growth and photosynthetic response experiment. The roots of each plant were separated from the soil and shaken manually to remove the loosely 
attached soil. Rhizosphere soil was considered soil that adhered to the roots and this was collected [38]. A single rhizosphere soil sample was obtained by pooling soil from three plants growing in the same pot. As a result, each treatment had six replicate rhizosphere samples due to the six replicate pots. Bulk soil samples were also collected from the same point at a depth of $0-10 \mathrm{~cm}$. Soil samples were mixed thoroughly, divided into two parts, stored in sterile $50 \mathrm{~mL}$ Falcon tubes, and transported to the laboratory. One part was kept at $4^{\circ} \mathrm{C}$ for analysis of soil $\mathrm{NH}_{4}{ }^{+}-\mathrm{N}$ and $\mathrm{NO}_{3}{ }^{-}-\mathrm{N}$, and to extract soil DNA within 3 days. The other part was air-dried for measurements of soil pH, total N (TN), total P (TP), total K (TK), soil organic C (SOC), available $\mathrm{P}(\mathrm{AP})$, available K (AK).

\section{Plant sampling measurements}

The total leaf area for each seedling was measured in the laboratory using a LI-3000A leaf area scanner (LI-COR Inc., USA). Root morphology including total root length, root surface area, and root volume was analyzed using a WinRhizo-V700 root scanner (Regent Instruments Inc., Quebec, Canada). The chlorophyll content was determined spectrophotometrically using $80 \%$ acetone as a solvent [49]. On the same leaf, a portable pulsemodulated fluorometer (PAM2100, Walz, Effeltrich, Germany) with the PamWin software was used to measure chlorophyll fluorescence $\left(F_{v} / F_{m)}\right.$.

The seedling biomass was determined by oven drying at $80^{\circ} \mathrm{C}$ for $72 \mathrm{~h}$. Specific leaf area (the one-sided area of a fresh leaf divided by its oven-dry weight) and specific root length (the ratio of root length to dry weight of fine roots) were measured following standard protocols [50]. $\mathrm{N}$ concentration in leaves and roots was measured using an elemental analyzer system (ECS 4024, Costech Inc., Italy). Plant shade response index and soil-plant feedback index were calculated based on plant biomass in shade and non-shade [16] or live and sterile soil [51].

\section{Soil physicochemical analyses}

Soil $\mathrm{pH}$ was measured using a pH meter (Mettler Toledo FE20, Switzerland) in a soil solution with a 1:2.5 soil: water ratio. $\mathrm{The}^{-}{ }^{+}-\mathrm{N}_{\text {and }} \mathrm{NO}_{3}{ }^{-}-\mathrm{N}$ were extracted with $2.0 \mathrm{M} \mathrm{KCl}$ and measured by a continuous flow analyzer (Flowsys, Systea Inc., Italy). Soil was processed for $\mathrm{C}$ content by first removing inorganic $\mathrm{C}$ through treatment with $1 \mathrm{M} \mathrm{HCl}$. Following removal of inorganic $\mathrm{C}$, soil organic $\mathrm{C}$ was analyzed using an auto-analyzer (Shimadzu, Kyoto, Japan). The total $\mathrm{N}$ in the soils was measured on an elemental analyzer (ECS 4024, Costech Inc., Italy). Total P was determined by digesting samples first with $\mathrm{HClO}_{4}-\mathrm{H}_{2} \mathrm{SO}_{4}$, and the molybdenum blue method using an ultraviolet-visible spectrophotometer was used for quantitation(UV-1000, AOE Instruments, Shanghai, China). Available soil P (AP) was extracted with $0.03 \mathrm{M}$ ammonium fluoride-hydrochloric acid and measured colorimetrically as described above. Total $\mathrm{K}$ was determined using $\mathrm{NaOH}$ fusion method, and the available $\mathrm{K}$ (AK) was extracted with 1.0 $\mathrm{M}$ ammonium acetate and measured by flame photometry (Model 410, Sherwood, England).

\section{Soil bacterial community analyses}

DNA extraction, PCR amplification, and high-throughput sequencing

Total soil DNA was extracted from $0.30 \mathrm{~g}$ of each soil sample using the Power Soil DNA extraction kit (MoBio Laboratories, Carlsbad, CA) as directed by the manufacturer's instructions. The following PCR primers were used for amplification targeting the V4 region of the bacterial $16 \mathrm{~S}$ rRNA gene: F515 (5'-GTGCCAGCMGCCGCGGTAA-3') and R806 (5'-GGACTACHVGGGTWTCTAAT-3'). Paired-end sequencing was performed at Beijing Genomics Institute (BGI)-Shenzhen, Shenzhen, China, using a paired 250-bp Illumina HiSeq 2500 sequencing platform according to the manufacturer's instructions.

\section{Sequence processing}

Illumina sequencing data were pair-assembled using FLASH software (v1.2.11) [52] with a minimal overlap length of 15 bp and mismatching ratio of overlapped region $\leq 0.1$. Sequences were clustered into operational taxonomic units (OTUs) at a $97 \%$ identity threshold using USEARCH (v7.0.1090) [53]. UCHIME (v4.2.40) against the SILVA database to filter out chimeric sequences. USEARCH GLOBAL was used to align representative sequences from individual OTUs [54]. These were taxonomically classified using the Ribosomal Database Project (RDP) Classifier v.2.2 based on the SILVA database, using a 0.6 confidence value as a cutoff.

\section{Statistical analyses}

Analysis of variance (ANOVA) according to the general linear model procedure of SPSS17.0 (SPSS Inc., Chicago, IL USA) was used to determine the effects of shade treatment, turfgrass species, and the interactions between these factors on plant physiological indicators and the influence of shade treatment on soil properties. The roles of shade stress, soil treatment and the interactions of shade stress and soil treatment in plant biomass, root: shoot ratios, and $\mathrm{N}$ content in OJ and LP seedlings were analyzed using two-way ANOVA. Values for the plant shade response index were also analyzed using two-way ANOVA, with soil treatments and species identity as the fixed factors. In addition, the soil-plant feedback index and dry biomass in OJ and LP were analyzed using two-way ANOVA, with light treatments and species identity as the fixed factors. Differences between treatment means were separated by Fisher's protected least significance difference (LSD) test at $P=0.05$. For these analyses, OTUs defined at $97 \%$ sequence similarity were used. Boxplots and heatmaps were obtained with the R package ggplot2 (v2.2.1). Rarefaction curves of observed OTUs were generated using R (v3.1.1). The differences in OTU composition between samples were displayed using principal component analysis (PCA). Alpha diversity [Richness, Shannon diversity index ( $\left.\mathrm{H}^{\prime}\right)$ and Simpson's Evenness (E)] was analyzed based on randomly rarefied OTU 
abundance matrices using mothur (v1.31.2). Bray-Curtis distances of bacterial communities using QIIME (v1.80) were used to analyze beta diversity. Principal coordinates analyses (PCOA), based on Bray-Curtis dissimilarity, were used to display differences in the composition of bacterial communities between OJ and LP rhizosphere soil treatments. Permutational multivariate analysis of variance (PERMANOVA) was conducted to test the significance of the Bray-Curtis dissimilarity. Kruskal-Wallis tests were performed using R software (kruskal. test function) to assess the impact of shade stress on soil bacterial community structure in both species. A value of $P<0.05$ was considered to be statistically significant.

To analyze the correlations between soil physicochemical parameters and bacterial community compositions, a Mantel test (9,999 permutations) with Spearman correlations of the $\mathrm{R}$ vegan package was used. Canonical correspondence analyses (CCA) were performed with the $\mathrm{R}$ vegan package (v2.4.2) to visualize the relationship between soil physicochemical properties and bacterial communities. For the CCA analyses, the correlation of the canonical axes with the explanatory matrix was determined with the general permutation test and the "envfit" function was used to analyze the significance of soil physicochemical factors on the composition of bacterial communities. To analyze the correlations between above-and below ground phenotypes and the composition of bacterial communities, pairwise fitting analysis was carried out using the "Im" function in the $\mathrm{R}$ vegan package.

Indicator species analysis was performed using the multipatt function implemented in the indicspecies package in $\mathrm{R}$ with 1000 permutations. The bioindicators of LP and OJ soil were designated as the OTUs of the core microbiome of LP or OJ soil under different treatments while also having abundances higher in OJ according to the permutation test $(P<0.05)$.

\section{Abbreviations}

AK: Available K; AP: Available P; CCA: Canonical correspondence analyses; OJ: Ophiopogon japonicus; OTUs: Operational taxonomic units; LP: Lolium perenne,RDP: Ribosomal Database Project; SOC: Soil organic C; TK: Total K; TN: Total N; TP: Total P; PCoA: Principal coordinates analyses; PERMANOVA: Permutational multivariate analysis of variance

\section{Declarations}

\section{Acknowledgements}

We thank Dr. Kaiwei Liu from BGI-Shenzhen for their advice on data analysis and constructive comments to this manuscript.

\section{Funding}

This research was supported by project Ph.D research start-up foundation of Northwest A \& F University (2452017195) and Postdoctoral Research Foundation of China (2018M631208). The funding agency had no role in the design of the study, collection, analysis, and interpretation of data, or in writing the manuscript.

\section{Availability of data and materials}

All sequence files described in this paper have been submitted to the National Center for Biotechnology Information (NCBI) Sequence Read Archive (SRA) database (accession number: SRP154594).

\section{Authors' contributions}

JF and TH conceived and designed the study. PS, YL, JG and DZ performed the experiments. JF and PY analyzed the data and wrote the manuscript. All the authors have read and approved the final manuscript.

\section{Ethics approval and consent to participate}

Not applicable.

\section{Consent for publication}

Not applicable.

\section{Competing interests}


The authors declare that they have no potential conflict of interest.

\section{Authors' Affiliations}

Department of grassland science, College of Grassland Agriculture, Northwest A\&F University, Yangling, Shaanxi, China.

\section{References}

1. Jiang YW, Duncan RR, Carrow RN. Assessment of low light tolerance of seashore paspalum and bermudagrass. Crop Sci. 2004;44:587-94.

2. Xu YF, Sun XL, Jin JW, Zhou H. Protective effect of nitric oxide on light-induced oxidative damage in leaves of tall fescue. J Plant Physiol. 2010;167:512-18.

3. Ciolfi A, Sessa G, Sassi M, Possenti M, Salvucci S, Carabelli M, Morelli G, Ruberti I. Dynamics of the Shade-Avoidance Response in Arabidopsis. Plant Physiol. 2013;163:331-53.

4. Kuehne C, Nosko P, Horwath T, Bauhus J. A comparative study of physiological and morphological seedling traits associated with shade tolerance in introduced red oak (Quercus rubra) and native hardwood tree species in southwestern Germany. Tree Physiol. 2014, 34:184-93.

5. Koh KJ, Bell GE, Martin DL. Shade and airflow restriction effects on creeping bentgrass golf greens. Crop Sci. 2003;43: 2182-88.

6. Hussain S, Iqbal N, Brestic M. Changes in morphology, chlorophyll fluorescence performance and Rubisco activity of soybean in response to foliar application of ionic titanium under normal light and shade environment. Sci Total Enviro. 2019;658:626-37.

7. Valladares F, Niinemets U. Shade tolerance, a key plant feature of complex nature and consequences. Annu Rev Ecol Evol S. 2008;39:237-57.

8. JIANG CD, WANG X, GAO HY, SHI L, CHOW WS. SYSTEMIC REGULATION OF LEAF ANATOMICAL STRUCTURE, PHOTOSYNTHETIC PERFORMANCE, AND HIGH-LIGHT TOLERANCE IN SORGHUM. PLANT PHYSIOL. 2011;155:1416-24.

9. Fu JJ, Chu XT, Sun YF, Yang LY, Xu YF, Hu TM. Exogenously applied nitric oxide (NO) alleviates shade-induced oxidative stress in tall fescue. J Hortic Sci Biotechnol. 2014;89:193-200.

10. Mishanin VI, Trubitsin BV, Benkov MA, Minin AA, Tikhonov AN. Light acclimation of shade-tolerant and light-resistant Tradescantia species: induction of chlorophyll a fluorescence and P700 photooxidation, expression of PsbS and Lhcb1 proteins. Photosynth Res. 2016;130:275-91.

11. LI L, LI XY, XU XW, LIN LS, ZENG FJ, CHEN FL. Assimilative branches and leaves of the desert plant Alhagi sparsifolia Shap. possesses a different adaptation mechanism to shade. Plant Physiol Biochem. 2014;74:239-45.

12. Bonfls CJW, Phillips TJ, Lawrence DM, Cameron-Smith P, Riley WJ, Subin ZM. On the infuence of shrub height and expansion on northern high latitude climate. Environ Res Lett. 2012;7:015503.

13. Friesen ML, Porter SS, Stark SC, von Wettberg EJ, Sachs JL, Martinez-Romero E. Microbially mediated plant functional traits. Ann Rev Ecol Evol Syst. 2011;42: 23-46.

14. Fry E, Johnson G, Hall A, Pritchard W, Bullock J, Bardgett R. Drought neutralises plant-soil feedback of two mesic grassland forbs. Oecologia. 2018;186:1113-25.

15. Dahl MB, Priemé A, Brejnrod A, Brusvang P, Lund M, Nymand J, Kramshøj M, Ro-Poulsen H, Haugwitz MS. Warming, shading and a moth outbreak reduce tundra carbon sink strength dramatically by changing plant cover and soil microbial activity. Scientific reports. $2017 ; 7: 16035$.

16. Xi NX, Bloor JMG, Wang Y, Chu CJ. Contribution of conspecific soil microorganisms to tree seedling light responses: Insights from two tropical species with contrasting shade tolerance. Environmental and Experimental Botany, 2019;166:103826.

17. Ma ZY, Behling S, Ford ED. The contribution of dynamic changes in photosynthesis to shade tolerance of two conifer species. Tree Physiol. 2014;34:730-43.

18. Ploschuk EL, Bado LA, Salinas M, Wassner DF, Windauer LB, Insausti P. Photosynthesis and fluorescence responses of Jatropha curcas to chilling and freezing stress during early vegetative stages. Environ Exp Bot. 2014;102:18-26.

19. Rutten G, Prati D, Hemp A, Fischer M. Plant-soil feedback in East-African savanna trees. Ecology. 2016;97:294-301.

20. Xi NX, Chu CJ, Bloor JMG. Plant drought resistance is mediated by soil microbial community structure and soil-plant feedbacks in a savanna tree species. Environ Exp Bot. 2018;155:695-701.

21. Wardle DA, Bardgett RD, Klironomos JN, Setala H, van der Putten WH, Wall DH. Ecological linkages between aboveground and belowground biota. Science. 2004;304:1629-33.

22. Kobe RK, Vriesendorp CF. Conspecific density dependence in seedlings varies with species shade tolerance in a wet tropical forest. Ecol Lett. 2011;14:503-10.

23. Bloom AJ, Chapin FS, Mooney HA. Resource limitation in plants-an economic analogy. Ann Rev Ecol Syst. 1985;16:363-92.

24. Acosta-Martínez V, Cotton J, Gardner T, Moore-Kucera J, Zak J, Wester D, Cox S. Predominant bacterial and fungal assemblages in agricultural soils during a record drought/heat wave and linkages to enzyme activities of biogeochemical cycling. Appl Soil Ecol. 2014;84:69-82. 
25. Tóth Z, Táncsics A, Kriszt B, Kröel-Dulay G, Ónodi G, Hornung E. Extreme effects of drought on composition of the soil bacterial community and decomposition of plant tissue: bacterial community and plant tissue decomposition. Eur J Soil Sci. 2017;68:504-13.

26. Ikenaga M, Guevara R, Dean AL, Pisani C, Boyer JN. Changes in community structure of sediment bacteria along the Florida coastal Everglades marsh-mangrove-seagrass salinity gradient. Microb Ecol. 2010;59:284-95.

27. Yuste JC, Fernandez-Gonzalez AJ, Fernandez-Lopez M, Ogaya R, Penuelas J, Sardans J, Lloret F. Strong functional stability of soil microbial communities under semiarid Mediterranean conditions and subjected to long-term shifts in baseline precipitation. Soil Biol Biochem. 2014;69:223-33.

28. Van Horn DJ, Okie JG, Buelow HN, Gooseff MN, Barrett JE, Takacs-Vesbacha CD. Soil microbial responses to increased moisture and organic resources along a salinity gradient in a Polar Desert. Appl Environ Microb. 2014;80:3034-43.

29. Hartmann M, Brunner I, Hagedorn F, Bardgett RD, Stierli B, Herzog C, Chen XM, Zingg A, Grafpannatier E, Rigling A, Frey B. A decade of irrigation transforms the soil microbiome of a semi-arid pine forest. Mol Ecol. 2017;26:1190-206.

30. Frossard A, Donhauser J, Mestrot A, Gygax S, Bååth E, Frey B. Long- and short-term effects of mercury pollution on the soil microbiome. Soil Biol Biochem. 2018;120:191-9.

31. Yandigeri MS, Meena KK, Singh D, Malviya N, Singh DP, Solanki MK, Yadav AK, Arora DK. Drought-tolerant endophytic actinobacteria promote growth of wheat (Triticum aestivum) under water stress conditions. Plant Growth Regul. 2012;68:411-20.

32. Singh BK, Munro S, Potts JM, Millard P. Influence of grass species and soil type on rhizosphere microbial community structure in grassland soils. Appl Soil Ecol. 2007;36:147-55.

33. Chodak M, Gołębiewski M, Morawska-Płoskonka J, Kuduk K, Niklińska M. Soil chemical properties affect the reaction of forest soil bacteria to drought and rewetting stress. Ann Microbiol. 2015;65:1627-37.

34. Dimkpa C, Weinand T, Asch F. Plant-rhizobacteria interactions alleviate abiotic stress conditions. Plant Cell Environ. 2009;32:1682-94.

35. Kaushal M, Wani SP. Plant-growth-promoting rhizobacteria: drought stress alleviators to ameliorate crop production in drylands. Ann Microbiol. 2016;66:35-42.

36. Kumar M, Mishra S, Dixit V, Kumar M, Agarwal L, Chauhan PS, Nautiyal CS. Synergistic effect of Pseudomonas putida and Bacillus amyloliquefaciens ameliorates drought stress in chickpea (Cicer arietinum L.). Plant Signal Behav. 2016;11:e1071004.

37. Etesami H, Maheshwari DK. Use of plant growth promoting rhizobacteria (PGPRs) with multiple plant growth promoting traits in stress agriculture: Action mechanisms and future prospects. Ecotox Environ Safe. 2018;156:225-46.

38. Wang C, Zheng MM, Hu AY, Zhu CQ, Shen RF. Diazotroph abundance and community composition in an acidic soil in response to aluminumtolerant and aluminum-sensitive maize (Zea mays L.) cultivars under two nitrogen fertilizer forms. Plant Soil. 2018;424:463-78.

39. Bouskill NJ, Lim HC, Borglin S, Salve R, Wood TE, Silver WL, Brodie EL. Pre-exposure to drought increases the resistance of tropical forest soil bacterial communities to extended drought. ISME J. 2013;7:384-94.

40. Ling N, Chen D, Guo H, Wei JX, Bai YF, Shen QR, Hu SJ. Differential responses of soil bacterial communities to long-term N and P inputs in a semi-arid steppe. Geoderma. 2017;292:25-33.

41. Pascual J, Blanco S, Ramos JL, van Dillewijn P. Responses of bulk and rhizosphere soil microbial communities to thermoclimatic changes in a Mediterranean ecosystem. Soil Biol Biochem. 2018;118:130-44.

42. Bottomley PJ, Taylor AE, Myrold DD. A consideration of the relative contributions of different microbial subpopulations to the soil N cycle. Front Microbiol. 2012;3:373.

43. Boyle SA, Yarwood RR, Bottomley PJ, Myrold DD. Bacterial and fungal contributions to soil nitrogen cycling under Douglas fir and red alder at two sites in Oregon. Soil Biol Biochem. 2008;40:443-51.

44. Nguyen LTT, Osanai Y, Lai KT, Anderson IC, Bange MP, Tissue DT, Singh BK. Responses of the soil microbial community to nitrogen fertilizer regimes and historical exposure to extreme weather events: Flooding or prolonged-drought. Soil Biol Biochem. 2018;118:227-36.

45. Bachar A, Al-Ashhab A, Soares MIM, Sklarz MY, Angel R, Ungar ED, Gillor O. Soil microbial abundance and diversity along a low precipitation gradient. Microb Ecol. 2010;60:453-61.

46. Naylor D, DeGraaf S, Purdom E, Coleman-Derr D. Drought and host selection influence bacterial community dynamics in the grass root microbiome. ISME J. 2017;11:2691-074.

47. Li B, Li YY, Wu HM, Zhang FF, Li CJ, Li XX, Lambers H, Li L. Root exudates drive interspecific facilitation by enhancing nodulation and N2 fixation. P Natl Acad Sci USA. 2016;113:6496-501.

48. Quinn GP, Keough MJ. Experimental design and data analysis for biologists. Cambridge University Press, New York, USA. 2002.

49. Lichtenthaler HK. Chlorophylls and carotenoids: Pigments of photosynthetic biomembranes. Method Enzymol. 1987;148:350-82.

50. Pérez-Harguindeguy N, Díaz S, Garnier E, Lavorel S, Poorter H, Jaureguiberry P, Bret-Harte MS, Cornwell WK, Craine JM, Gurvich DE, Urcelay C, Veneklaas EJ, Reich PB, Poorter L, Wright IJ, Ray P, Enrico L, Pausas JG, de Vos AC, Buchmann N, Funes G, Quétier F, Hodgson JG, Thompson K, Morgan HD, ter Steege H, Sack L, Blonder B, Poschlod P, Vaieretti MV, Conti G, Staver AC, Aquino S, Cornelissen JHC. New handbook for standardised measurement of plant functional traits worldwide. Aust J Bot. 2013;61:167-234.

Page $10 / 18$ 
51. Brinkman E, Van der Putten WH, Bakker EJ, Verhoeven KJF. Plant-soil feedback: experimental approaches, statistical analyses and ecological interpretations. J Ecol. 2010;98: 1063-73.

52. Magoc T, Salzberg S. FLASH: Fast length adjustment of short reads to improve genome assemblies. Bioinformatics. 2011;27:2957-63.

53. Edgar RC. UPARSE: Highly accurate OTU sequences from microbial amplicon reads. Nat Methods. 2013;10:996-8.

54. Wang Q, Garrity GM, Tiedje JM, Cole JR. Naive Bayesian classifier for rapid assignment of rRNA sequences into the new bacterial taxonomy. Appl Environ Microb. 2007;73: 5261-67.

\section{Tables}

Table 1 Responses of soil physicochemical variables to shade treatment. Values are the means(SD) of six pot replicates. Different lowercase or capital letters indicate significant differences ( $P<0.05$, LSD test) in OJ (Ophiopogon japonicus, shade tolerant) or LP (Lolium perenne, shade-intolerant) soil. $* * * P<0.001, * * P<0.01, * P<0.05$

\begin{tabular}{|c|c|c|c|c|c|c|c|c|c|c|}
\hline Soil sample & $\begin{array}{l}\text { Total N } \\
\left(\mathrm{g} \mathrm{kg}^{-1}\right) \\
\end{array}$ & $\begin{array}{l}\text { Organic C } \\
\left(\mathrm{g} \mathrm{kg}^{-1}\right)\end{array}$ & Soil C:N & $\begin{array}{l}\text { Total P } \\
\left(\mathrm{g} \mathrm{kg}^{-1}\right)\end{array}$ & $\begin{array}{l}\text { Total K } \\
\left(\mathrm{g} \mathrm{kg}^{-1}\right) \\
\end{array}$ & $\begin{array}{l}\mathrm{NH}_{4}^{+}-\mathrm{N} \\
\left(\mathrm{mg} \mathrm{kg}^{-1}\right)\end{array}$ & $\begin{array}{l}\mathrm{NO}_{3}{ }^{-} \mathrm{N} \\
\left(\mathrm{mg} \mathrm{kg}^{-1}\right)\end{array}$ & $\begin{array}{c}\text { Available P } \\
\left(\mathrm{mg} \mathrm{kg}^{-1}\right)\end{array}$ & $\begin{array}{l}\text { Available K } \\
\left(\mathrm{mg} \mathrm{kg}^{-1}\right)\end{array}$ & $\mathrm{PH}$ \\
\hline OJ.0d & $1.07(0.23)$ & $24.38(0.27)$ & $22.79(1.79)$ & $0.52(0.045) \mathrm{b}$ & $17.19(0.19) \mathrm{b}$ & $6.99(0.026) \mathrm{a}$ & $2.08(0.026) d$ & $0.40(0.014) \mathrm{b}$ & $140.35(11.92)$ & $7.46(0.029)$ \\
\hline OJ.L.14d & $1.19(0.19)$ & $24.21(1.97)$ & $20.34(1.70)$ & $0.58(0.035) a$ & $18.14(0.12) a$ & $2.91(0.61) b$ & $7.79(2.12) \mathrm{b}$ & $0.47(0.024) b$ & $162.79(22.92)$ & $7.41(0.092)$ \\
\hline OJ.S.7d & $1.08(0.14)$ & $21.97(4.04)$ & $20.34(1.38)$ & $0.51(0.05) \mathrm{b}$ & $17.83(0.36) \mathrm{a}$ & $2.15(0.89) b$ & $5.84(0.53) \mathrm{bc}$ & $1.16(0.033) \mathrm{a}$ & $162.02(36.03)$ & $7.67(0.089)$ \\
\hline OJ.S.14d & $1.09(0.16)$ & $22.13(3.62)$ & $20.30(1.21)$ & $0.57(0.040) a$ & $16.98(0.20) \mathrm{b}$ & $2.63(0.26) b$ & 11.64(2.59)a & $1.47(0.024) \mathrm{a}$ & $136.83(6.09)$ & $7.36(0.061)$ \\
\hline LP.0d & $1.24(0.09)$ & $25.36(0.87)$ & $20.45(0.66)$ & $0.54(0.032) \mathrm{b}$ & $16.88(0.13) \mathrm{bc}$ & $4.78(0.96) \mathrm{b}$ & $0.84(0.15) \mathrm{d}$ & $3.56(0.49) \mathrm{a}$ & $176.01(5.61)$ & $7.51(0.085)$ \\
\hline LP.L.7d & $1.21(0.02)$ & $21.88(0.74)$ & $18.08(0.73)$ & $0.68(0.11) a$ & $19.18(0.96) a$ & $4.67(0.47) \mathrm{b}$ & $3.17(0.201) \mathrm{c}$ & $2.33(0.85) b$ & $153.59(15.53)$ & $7.49(0.093)$ \\
\hline LP.L.14d & $1.17(0.15)$ & $24.99(1.27)$ & $21.36(1.76)$ & $0.60(0.021) \mathrm{ab}$ & $17.36(0.41) b$ & 5.94(1.44)a & $4.28(0.092) \mathrm{b}$ & $3.30(1.02) \mathrm{a}$ & $177.69(41.05)$ & $7.39(0.13)$ \\
\hline LP.S.7d & $1.12(0.10)$ & $22.97(3.19)$ & $20.51(1.09)$ & $0.59(0.015) a b$ & $17.56(0.38) b$ & $5.08(0.62) \mathrm{ab}$ & $5.12(0.25) \mathrm{b}$ & $3.03(0.46) \mathrm{a}$ & $143.13(8.82)$ & $7.42(0.25)$ \\
\hline LP.S.14d & $1.06(0.05)$ & $21.95(2.79)$ & $20.51(2.50)$ & $0.56(0.015) \mathrm{b}$ & $15.72(0.04) \mathrm{C}$ & $6.23(0.43) \mathrm{a}$ & $6.55(0.76) a$ & $0.68(0.036) \mathrm{C}$ & $142.67(3.16)$ & $7.65(0.061)$ \\
\hline \multicolumn{11}{|c|}{ F value for ANOVA } \\
\hline $\begin{array}{l}\text { Treatments } \\
\text { (T) }\end{array}$ & 0.504 & 0.919 & 0.738 & $3.279^{*}$ & $12.394^{* * *}$ & $4.302^{*}$ & $37.691^{* * *}$ & $1.910^{*}$ & 1.879 & 1.562 \\
\hline Species (S) & 0.328 & 0.105 & 1.885 & 2.430 & 0.310 & $22.301^{* * *}$ & $35.171^{* * *}$ & $0.114^{*}$ & 0.023 & 0.545 \\
\hline
\end{tabular}

\section{Figures}



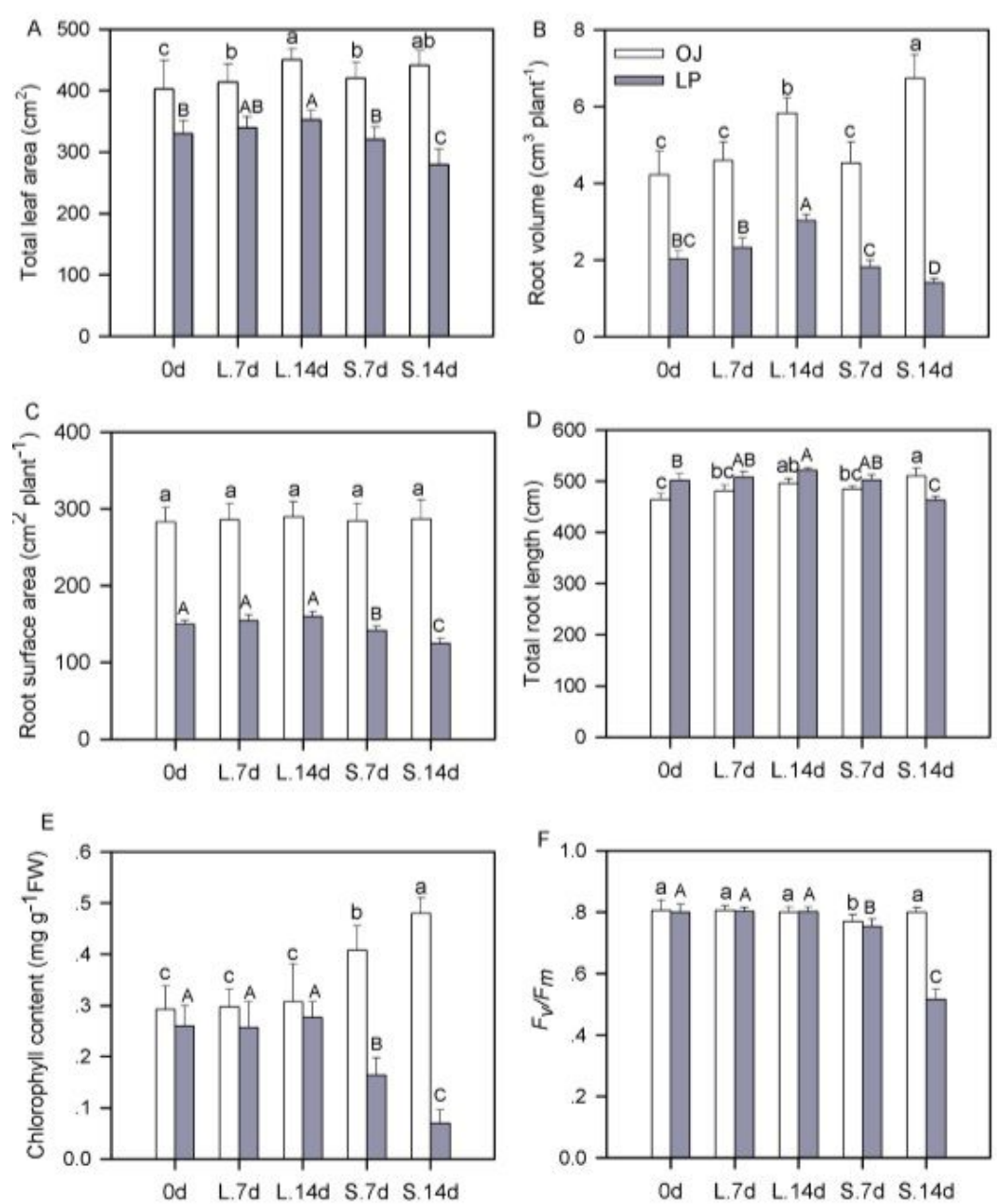

\section{Figure 1}

Plant total leaf area (A), total root length (B), root surface area (C), and root volume (D), chlorophyll content (E), and chlorophyll fluorescence (Fv/Fm) (F) of shade-tolerant OJ (Ophiopogon japonicus) and shade-intolerant LP (Lolium perenne) under shade stress. Values are the means \pm SD of six pot replicates. Lowercase or capital letters indicate significant differences $(P<0.05$, LSD test) in OJ or LP 

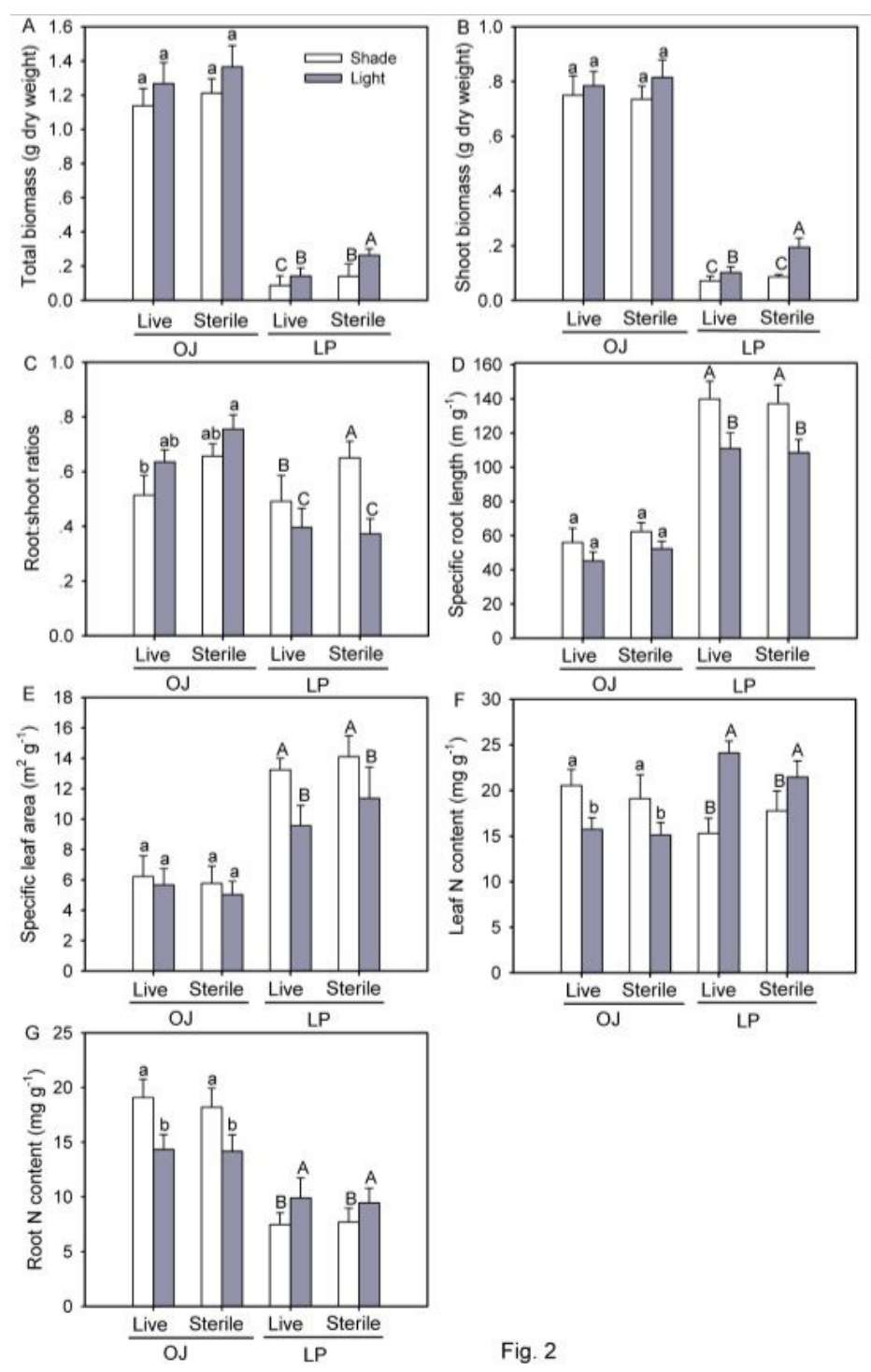

Fig. 2

\section{Figure 2}

Effects of shade and soil treatments on (A) total biomass, (B) shoot biomass, (C) root:shoot ratios, (D) specific stem length, (E) specific leaf area, (F) leaf $\mathrm{N}$ content, and (G) root $\mathrm{N}$ content of OJ (Ophiopogon japonicus) and LP (Lolium perenne). Values are the means \pm SD of six replicates. Lowercase or capital letters indicate significant differences $(P<0.05$, LSD test) in OJ or LP 

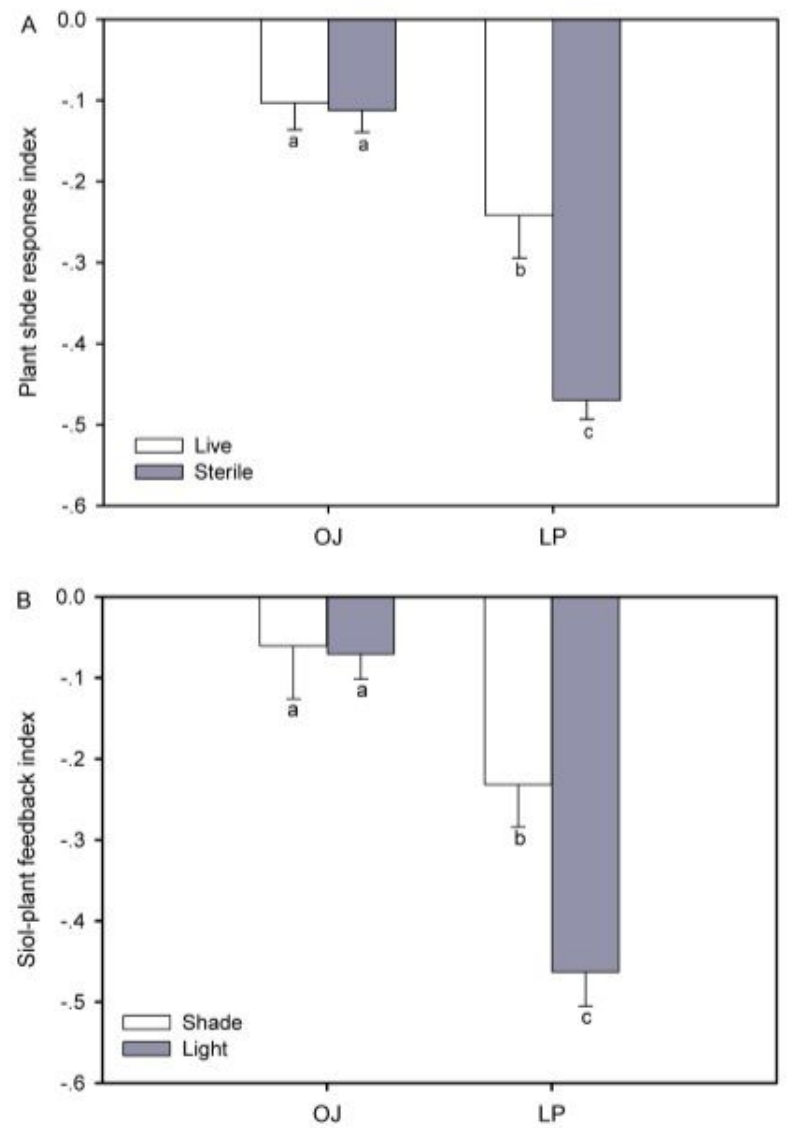

Figure 3

Plant shade response index (A) in live or sterile soil treatments and (B) soil-plant feedback index under highlight and shade conditions. Indices are based on seedling biomass of OJ (Ophiopogon japonicus) and LP (Lolium perenne). Values are the means \pm SD of six replicates. Lowercase or capital letters indicate significant differences ( $<0.05$, LSD test) in OJ or LP 
A

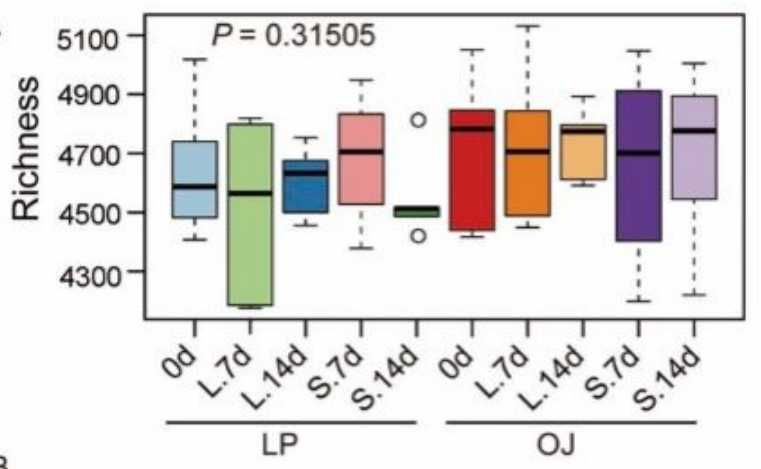

B
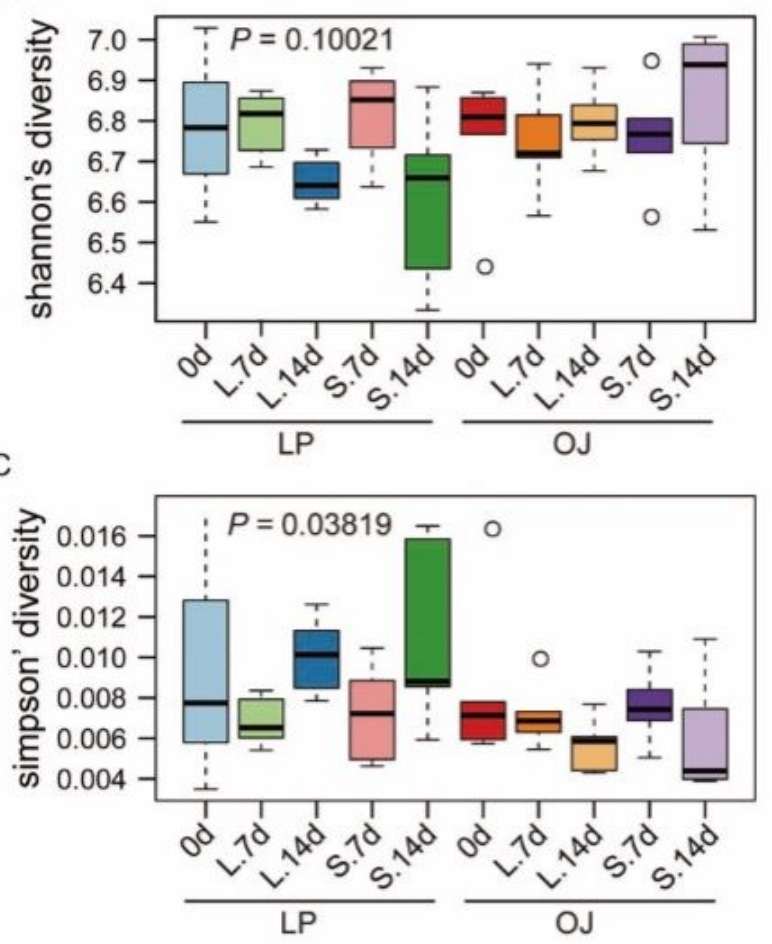

Figure 4

Boxplots of Richness (A), Shannon's diversity index (B) and Simpson's Evenness (C)] of bacterial communities based on OTUs defined at $97 \%$ sequence similarity. Black dots represent soil samples outliers 


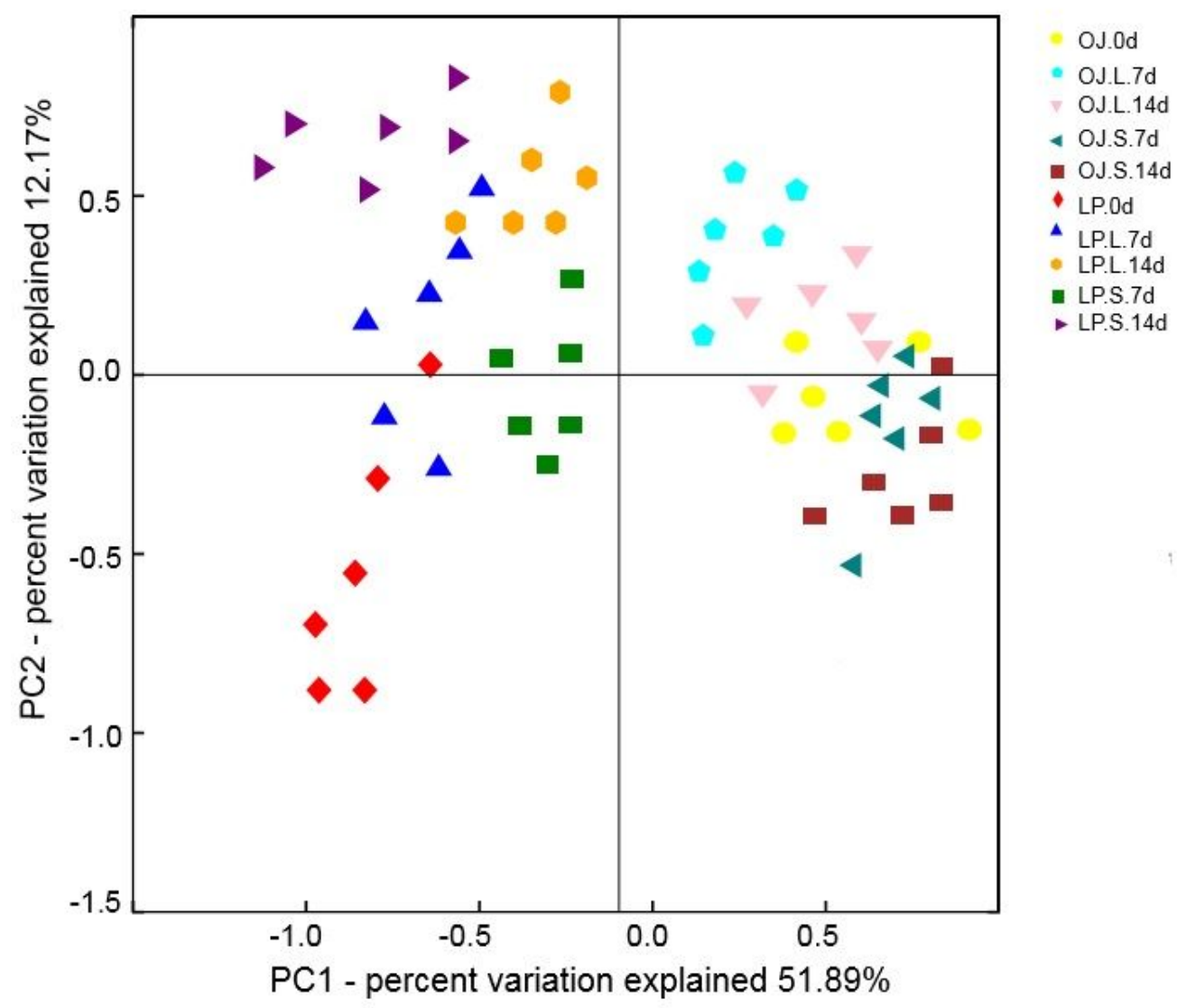

Figure 5

Principal coordinates analysis (PCOA) based on Bray-Curtis distances between rhizosphere soil bacterial communities in shade-tolerant OJ and shade-intolerant LP under shade stress

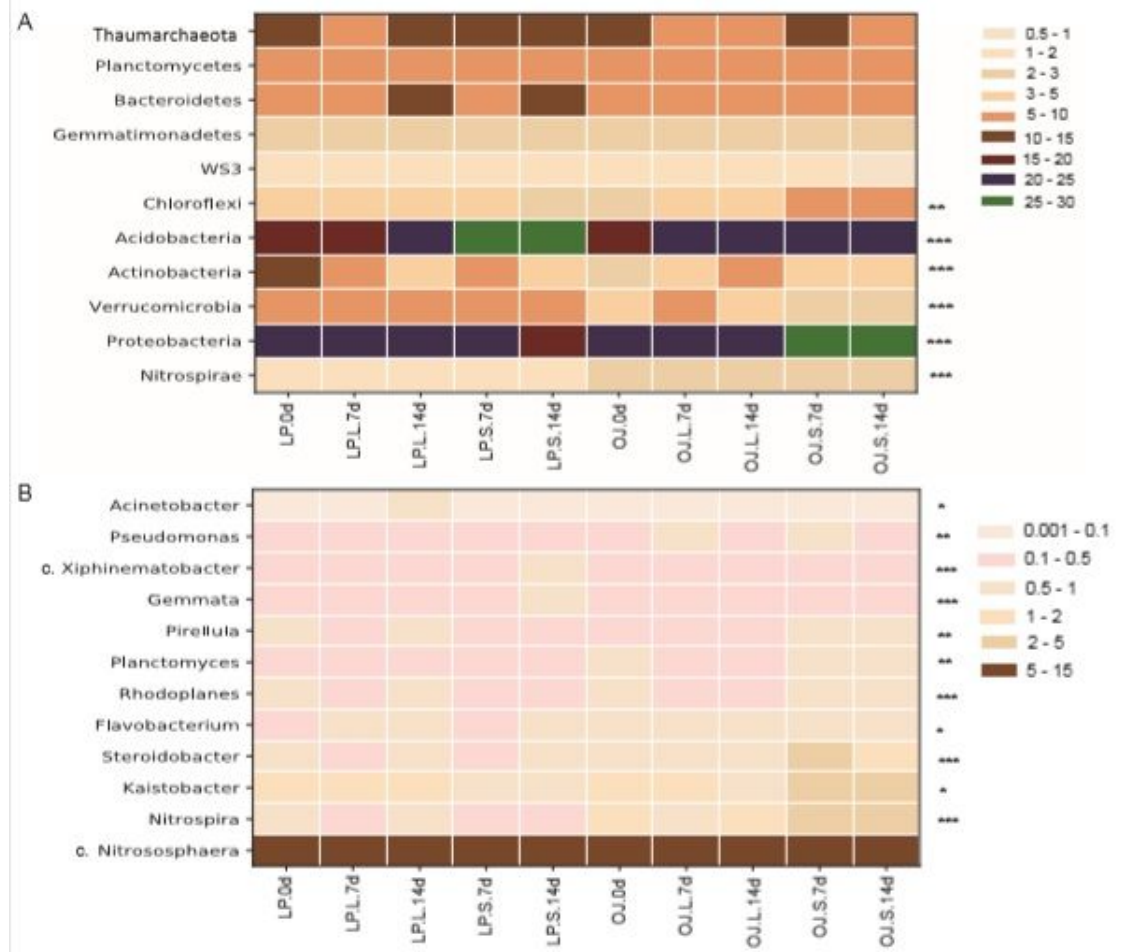

Figure 6 
Changes in the bacterial community composition at the phylum level (relative abundance $>1 \%, A$ ), and genus level (relative abundance $>0.5 \%$, B) under shade stress. Asterisks indicate statistically significant differences according to Kruskal-Wallis tests ( ${ }^{\star} P<0.05 ; * \star P<0.01$ and $\left.{ }^{\star \star *} P<0.001\right)$
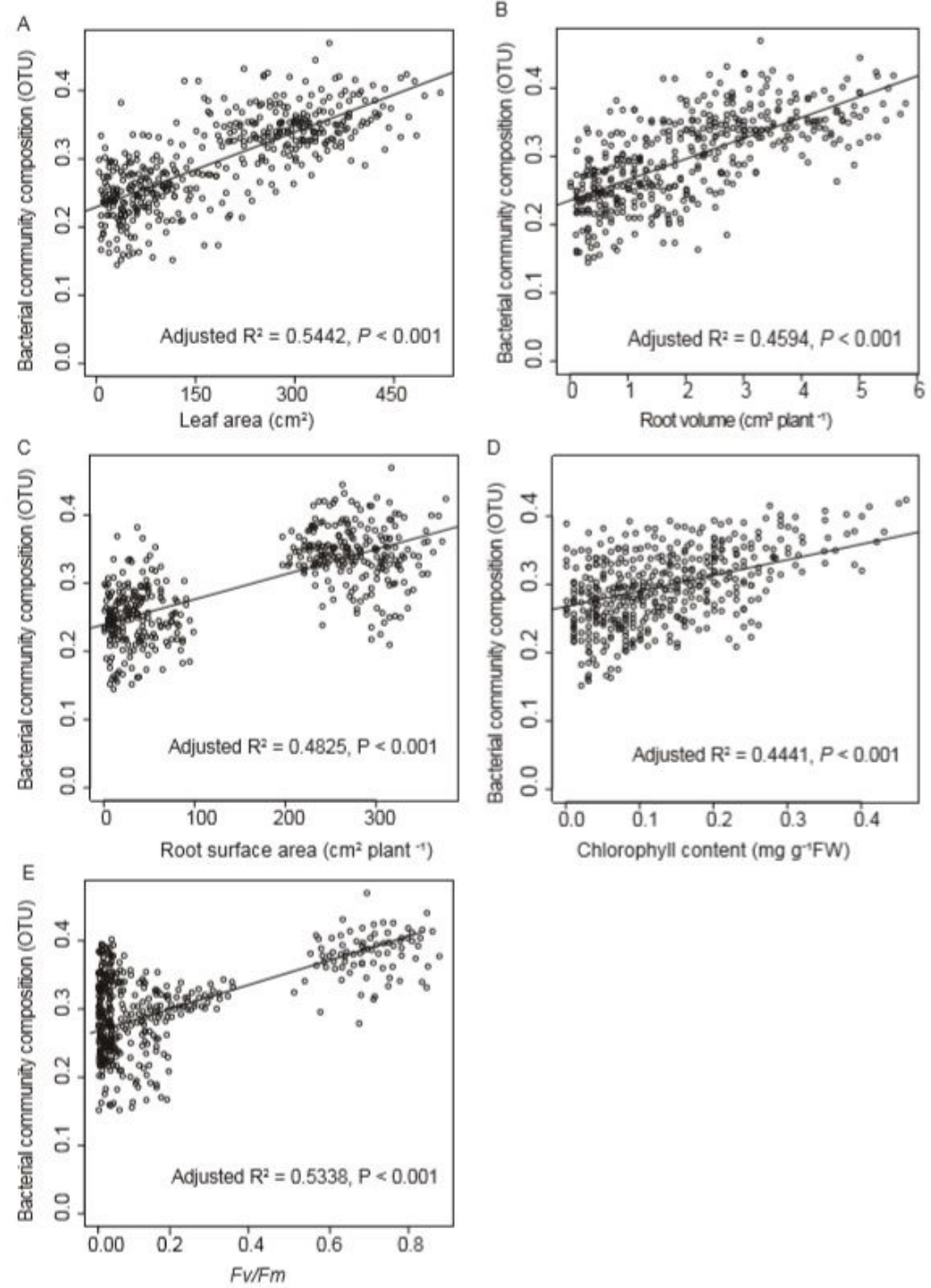

\section{Figure 7}

Relationships between total leaf area (A), root volume (B), root surface area (C), Fv/Fm (D), and chlorophyll content (E) in bacterial community composition under shade stress. The relationship between total root length and bacterial community composition was not significant (data not shown). The plot shows the $95 \%$ confidence interval of the fit 

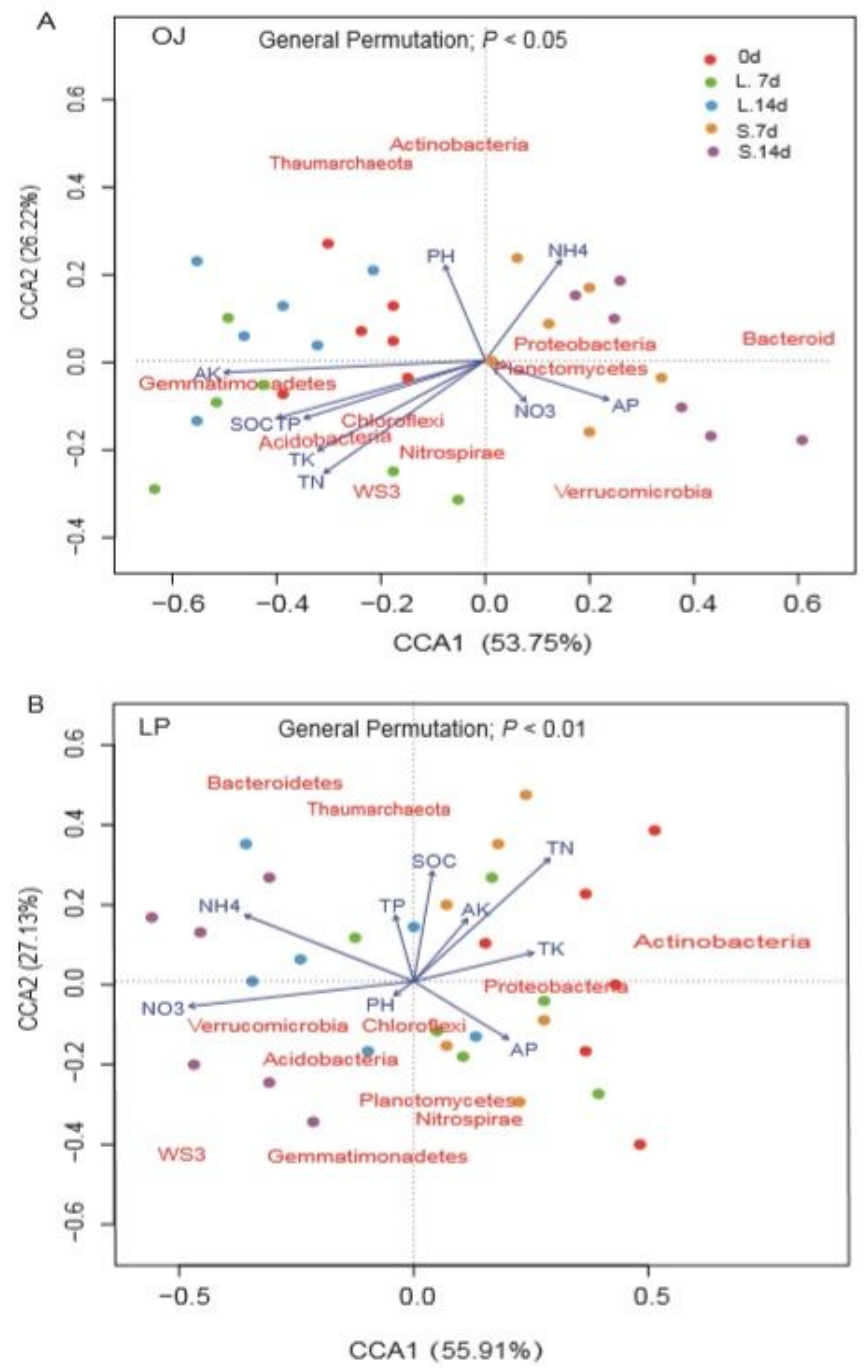

Figure 8

Canonical correspondence analysis (CCA) of bacterial communities based on Bray Curtis distances in rhizosphere soil bacterial communities of OJ (A) and LP (B) under shade stress. Arrows indicate the direction and magnitude of bacterial taxa associated with soil physicochemical characteristics. Permutation tests confirmed the effect of the soil factors as drivers of the bacterial community

\section{Supplementary Files}

This is a list of supplementary files associated with this preprint. Click to download.

- Additionalfile1.xls

- Additionalfile4.pdf

- Additionalfile8.xlsx

- Additionalfile7.xlsx

- Additionalfile3.xls

- Additionalfile5.pdf

- Additionalfile2.xls

- Additionalfile6.xlsx 